\title{
The Influence of Exercise Empowerment on Life Stress
}

\author{
Tonya M. Parker*, Colleen A. Lewis, Christina M. Beaudoin \\ Department of Movement Science, Grand Valley State University, 1 Campus Drive, Allendale, MI 49401, USA \\ Corresponding Author: Tonya M. Parker, E-mail: parkert@gvsu.edu
}

\section{ARTICLE INFO}

\section{Article history}

Received: August 05, 2017

Accepted: October 05, 2017

Published: October 31, 2017

Volume: 5 Issue: 4

Conflicts of interest: None

Funding: This research did not receive any specific grant from funding agencies in the public, commercial, or not-for-profit sectors.

\begin{abstract}
Background: Psychological stress - when an individual perceives that the environment exceeds their ability to meet the demands placed on them - is common in college students and exercise, and specifically instructional physical activity courses, is frequently cited as a one method of stress reduction. Objective: Determine any relationship between exercise empowerment and perceived life stress for those participating in instructional physical activity courses (IPAC). Methods: All undergraduate students $(\mathrm{n}=3388)$ enrolled in IPAC in 15 -week IPAC at a large university were surveyed on perceived life stress (PSS), empowerment in exercise (EES), and specific demographic variables. Results: 944 of 3388 enrolled students (Nov. 2015, April 2016) completed the survey. The data revealed GPA $(p<0.002)$, sex $(p<0.000)$, and EES $(p<0.001)$ showed differences for PSS. It was determined that EES, sex, and GPA predicted PSS differently for students according to their year in college. Conclusions: For freshman and seniors, sex and lower GPA were a stronger predictor of PSS with no mitigating effect of exercise empowerment. For sophomores and juniors the level of life stress was lower at higher levels of exercise empowerment. These findings support a complex relationship between exercise empowerment and life stress. While exercise is cited as a method for stress reduction the relationship between exercise empowerment and life stress for college-aged students is not as straightforward as it may seem.
\end{abstract}

Key words: Exercise, Life Stress, Physical Activity, Empowerment, University

\section{INTRODUCTION}

Life stress comes in many forms: family, friends, work, money, and unexpected events. Psychological stress occurs when an individual perceives that the environment - their daily life - exceeds their ability to meet the demands placed on them or that the response to events indicate an overload (Cohen, Janicki-Deverts, \& Miller, 2007). At the center of life stress is the feeling of control over daily life. Chronic stress has been implicated as a risk factor in a host of diseases: depression, anxiety, and other negative mental health states; cardiovascular disease; delayed wound healing; upper respiratory infections and other infectious diseases; and autoimmune diseases (Cohen \& Janicki-Deverts, 2102) as well as changes to more immediate concerns, like slowed decision making (Hepler, 2015). Similarly, for college students, life includes many stressors (Knowlden, Hackman, \& Sharma, 2016). Physical activity and healthy life choices can be pushed into the background when assignments, exams, work, and personal life demand time and attention. In one survey of health behaviors, 30.5 percent of college students reported that stress had impacted their academic performance leading to a lower grade on an exam, project, or course, dropping the course, and/or a significant disruption in their academic work (ACHA-NCHA, 2012).
For many students, healthy life choices during college can be difficult. Unfortunately, of college students surveyed, 21.1 percent reported zero days of moderate-intensity aerobic exercise and 35.9 percent reported zero days of vigorous aerobic activity (ACHA-NCHA, 2012). Participation in a structured 1-credit instructional physical activity course (IPAC) may therefore represent a chance to balance the stress of college life. A key component of the IPAC is the structured instructional nature of the experience rather than the physical activity alone. Within an instructional physical activity course students are further developing their knowledge, skills, and ability to be physically active. According to Moore and Fry (2014) being physically active enhances empowerment or the ability to persist and overcome future participation barriers. Exercise empowerment has been defined as "an increased sense of one's ability to control and reach their physical fitness and health potential through continued exercise" (Moore \& Fry, 2014). Through empowerment an individual develops a stronger perception of control of their health and fitness status. Participation in the IPAC develops greater knowledge and understanding of movement principles, concepts, and strategies thus supporting physical activity and health-related behaviors. Ideally college students enrolled in an IPAC are empowered by their improved move- 
ment competence and physical health which subsequently leads to greater self-confidence, feelings of greater control, and less life stress.

To better understand the relationship between perceived life stress and exercise empowerment the authors surveyed undergraduate students in structured instructional physical activity courses. The authors also sought to determine if this relationship varied according to important demographic variables such as sex, year in school, and performance in school as measured through GPA.

\section{METHODS}

\section{Participants and Procedures}

Human research review approval was granted to survey all students $(n=3388)$ enrolled in a 15 -week elective 100 -level skill development physical activity course at a large Midwestern public university in the fall and spring semesters. Surveys were delivered via the online course management system and instructors were informed and asked to encourage students to participate. There were no incentives offered to either the student or instructor for participation and the survey could be exited at any time. The survey was open for two weeks and 3 reminder emails were sent throughout that time. The survey was administered after midterm exams and at least 2 weeks before final exams to mitigate anticipated increases in overall stress levels.

\section{Measures}

The survey consisted of three sections: (a) demographic questions, (b) Empowerment in Exercise Scale, (c) Perceived Stress Scale.

\section{Demographics}

The demographic questions included sex identification (Male, Female, Transgender, Transsexual, Prefer not to answer), self-identified year in school (Freshman, Sophomore, Junior, Senior), and the self-reported estimate of overall GPA (Below 1.0, 1.0 - 1.5, 1.5 - 2.0, 2.0 - 2.5, 2.5 - 3.0, 3.0 - 3.5, and above 3.5).

\section{Empowerment in Exercise Scale (EES)}

The EES contains questions about the participants' sense of their control of and ability to reach their physical fitness and health potential through continued exercise, including longer term benefits from their current exercise class experience (Moore \& Fry, 2014). The EES consists of 5 questions rating participants' degree of agreement/disagreement ( $1=$ strongly disagree and $5=$ strong agree $)$ with statements about confidence in their ability to perform the activity and knowledge and understanding of the activity. Additional questions evaluate confidence in completing the activity independently and in the value of the instructor's feedback. The EES has a range of values from 5 to 25, with a higher value representing greater empowerment in exercise. A confirmatory factor analysis was conducted and McDonald's Coefficient omega represented good internal consistency $(\Omega=0.89$; Moore \& Fry, 2014).

\section{Perceived Stress Scale (PSS)}

The 10-item PSS examines the frequency with which participants perceive situations in their life as stressful relative to their ability to cope $(0=$ never to $4=$ very often; Cohen, Kamark \& Mermelstein, 1983). This scale has a range of 0 to 40 with higher scores representing greater life stress and has been studied at length and found to have good reliability $(r=0.84$; Cohen et al., 1983).

\section{Data Analysis}

General linear modelling using SPSS with numerical scoring of PSS as the dependent variable and numeric scoring of EES as the covariate, was analyzed by demographic variables: year in school, GPA, and sex. Significance level was set at $p<0.05$.

\section{RESULTS}

The survey was administered to 3388 students enrolled in 143 sections (fall $=81$; spring $=62$ ) of SDAC during the fall of $2015(n=1854)$ and spring of $2016(n=1534)$ semesters. Total number of completed surveys was 944 (27.9\% response rate).

Demographic variables were organized for analysis by collapsing GPA into 4 categories: below 2.5, 2.5 to 3.0, 3.0 to 3.5 , and above 3.5 . The total number of students with GPA below 2.5 is understandably low among upper division students since university policy will not allow those below 2.0 GPA to re-enroll in classes. All these individuals were collapsed into one group to identify those who may be not be performing well academically. Additionally, eight individuals preferred not to share their sexual identity or identified as transgender. These individuals, as well as any with incomplete data, were removed from the current dataset. Demographic variables can be found in Table 1.

The Omnibus test of the model demonstrated significance at $p<0.000$. Further examination reveals year in school to have no significant main effects $(p<0.691)$ while GPA $(p<0.002)$, sex $(p<0.000)$, and EES $(p<0.001)$ showed differences. Since year in school showed no main effects, the model was split according to this variable for further analysis. Scores for EES and PSS can be found in Table 2 .

It was discovered that EES, sex, and GPA predicted PSS differently for students from each year in college. For freshman, their empowerment did not have predictive value for their stress level, instead a sex and GPA difference was uncovered. Women reported greater stress than men $(p<0.000)$, and those in the lower two categories of GPA (below 2.5, $p<0.000 ; 2.5$ to 3.0, $p<0.019$ ) reported greater stress than those scoring above 3.5. For sophomores, the sex differences remain the same as their freshman classmates, but additionally EES predicted stress level. As EES decreas- 
es (less empowerment) the reported life stress increases $(p<0.003)$.

The picture changes for the upper-division students: the only significant predictor of PSS for junior students in our model is their EES score $(p<0.000)$ with less empowerment associated with greater stress. The sex difference reappears with senior women, who report greater life stress regardless of their empowerment, than their male counter-

Table 1. Number (N) of respondents by GPA, Sex, and Year in school

\begin{tabular}{lcccc}
\hline GPA & FR & SO & JR & SR \\
\hline Women & & & & \\
Less than 2.5 & 12 & 4 & 6 & 9 \\
$2.5-3$ & 46 & 25 & 20 & 33 \\
3-3.5 & 98 & 68 & 43 & 63 \\
Above 3.5 & 93 & 54 & 44 & 88 \\
Total (N) & 249 & 151 & 113 & 193 \\
Men & & & & \\
Less than 2.5 & 11 & 7 & 3 & 3 \\
2.5-3 & 18 & 9 & 8 & 13 \\
3-3.5 & 36 & 14 & 18 & 30 \\
Above 3.5 & 15 & 9 & 9 & 23 \\
Total (N) & 80 & 39 & 38 & 69 \\
\hline
\end{tabular}

$\mathrm{FR}=$ Freshman, $\mathrm{SO}=$ Sophomores, $\mathrm{JR}=$ Juniors, $\mathrm{SR}=$ seniors parts $(p<0.000)$. There was one additional difference noted in GPA for seniors with those between 2.5 to 3.0 reporting greater stress than those above $3.5(p<0.001)$.

\section{DISCUSSION}

There are similar indicators for life stress for freshman and seniors with sex and GPA differences observed. The women reported greater stress than men. Irrespective of sex, those with GPAs below 3.0 reported greater stress than those students with a GPA above 3.5. Sophomores have a slightly different picture. The sex differences remain and GPA differences are exchanged for the EES score in predictive ability. Juniors seem to be a unique group with only EES score predicting PSS.

College students take for-credit IPAC for a variety of reasons. Studies reported reasons as diverse as 'for enjoyment' and 'credits for graduation' as well as 'to stay fit' and 'to relieve stress (authors, in press; Lumpkin \& Avery, 1986). While physical activity is frequently cited as a method for stress reduction, the relationship between empowerment through instructional physical activity and life stress for college-aged students is not simple and straightforward (Barney, Benham, \& Haslam, 2014; Gerber, Brand, Elliot, Holsboer-Trachsler, \& Puhse, 2016). Sophomores and juniors show the effects of higher empowerment and lower life stress, however first year students and seniors do not seem to show the benefit of empowerment through exercise to balance the stress of GPA and sex.

Table 2. Mean (standard deviation) Scores for the Perceived Stress Scale (PSS) and Empowerment in Exercise Scale (EES) by GPA, Sex, and Year in School

\begin{tabular}{|c|c|c|c|c|}
\hline \multirow[t]{2}{*}{ GPA } & \multicolumn{2}{|c|}{ Women } & \multicolumn{2}{|c|}{ Men } \\
\hline & PSS & EES & PSS & EES \\
\hline \multicolumn{5}{|l|}{ FR } \\
\hline Less than 2.5 & $25.8(4.7)$ & $21.7(2.4)$ & $19.0(4.4)$ & $21.8(2.4)$ \\
\hline $2.5-3$ & $22.1(4.8)$ & $21.2(2.9)$ & $18.7(5.6)$ & 21.7 (2.9) \\
\hline $3-3.5$ & $20.7(4.6)$ & $21.4(2.9)$ & $18.6(4.0)$ & $21.9(3.3)$ \\
\hline Above 3.5 & $20.3(4.0)$ & $21.1(3.1)$ & $17.7(4.2)$ & $20.9(4.7)$ \\
\hline \multicolumn{5}{|l|}{ SO } \\
\hline Less than 2.5 & $23.3(4.8)$ & $22.0(2.2)$ & $17.9(5.9)$ & $24.1(1.5)$ \\
\hline $2.5-3$ & $21.0(4.7)$ & $21.7(2.9)$ & $19.4(3.0)$ & $23.8(2.0)$ \\
\hline $3-3.5$ & $20.5(4.6)$ & $22.4(2.5)$ & $18.3(5.4)$ & $22.7(2.2)$ \\
\hline Above 3.5 & $21.1(3.9)$ & $21.7(2.5)$ & $15.8(6.4)$ & $23.4(1.8)$ \\
\hline \multicolumn{5}{|l|}{$J R$} \\
\hline Less than 2.5 & $18.0(6.9)$ & $20.7(4.4)$ & $15.0(6.2)$ & $25.0(0.0)$ \\
\hline $2.5-3$ & $20.4(3.5)$ & $21.9(2.3)$ & $21.6(4.1)$ & $21.6(4.0)$ \\
\hline $3-3.5$ & $21.2(4.4)$ & $21.8(2.6)$ & $21.2(4.7)$ & $21.8(2.6)$ \\
\hline Above 3.5 & $21.2(3.7)$ & $21.3(3.4)$ & $16.2(4.1)$ & $21.9(5.0)$ \\
\hline \multicolumn{5}{|l|}{ SR } \\
\hline Less than 2.5 & $21.0(3.0)$ & $21.9(3.8)$ & $19.3(2.5)$ & $22.3(2.3)$ \\
\hline $2.5-3$ & $22.9(4.6)$ & $21.9(2.4)$ & $21.1(5.4)$ & $20.7(4.6)$ \\
\hline $3-3.5$ & $21.5(4.3)$ & $21.6(2.9)$ & $17.5(4.6)$ & $21.0(4.2)$ \\
\hline Above 3.5 & $20.7(3.7)$ & $21.9(2.5)$ & $18.0(3.7)$ & $22.0(4.3)$ \\
\hline
\end{tabular}

$\mathrm{FR}=$ Freshman, $\mathrm{SO}=$ Sophomores, $\mathrm{JR}=$ Juniors, $\mathrm{SR}=\mathrm{S}$ eniors 
Supporting the role of empowerment through exercise being associated with less life stress, some students reported (sophomores, juniors) the level of life stress was lower with higher levels of empowerment. While these findings do not support causative conclusions, they do mirror other studies (Strahler, Doerr, Ditzen, Linnemann, Skoluda, \& Nater, 2016). Only in conditions of lower life stress can the positive benefits of regular exercise be seen. Sophomores and juniors have successfully made the adjustment to college life with which first year students may still struggle. It may be extrapolated that juniors do not have the immediacy of graduation increasing their life stress as the seniors might. Literature on life stress examined by year in school has not been explored. Ngyuyen-Michel and colleagues (2006) examined different college settings and the relationship between self-reported exercise and hassles. While significant differences were found for college setting (community college vs 4-year university) with regard to exercise and perceived stress/hassles, it should be noted that the exercise levels were self-reported recall and the student body at the colleges were treated as monolithic, not examining year in school as a influencing factor. The present study specifically utilizes IPAC in order to avoid the variability inherent in self-report of physical activity. All participants were all enrolled in a twice weekly instructional activity course that met for the same amount of time.

For first year students and seniors, the sex of the student and lower GPA was a stronger predictor of overall perceived life stress with women reporting an average of three points higher perceived stress than their male classmates. This is in line with previous work, where women have traditionally reported experiencing a greater number and severity of stressors compared with men and often perceive stress more negatively (Cohen \& Janicki-Deverts, 2006; Jones, Mendenhall, \& Myers, 2016). This may be related to a broader cultural shift in self-evaluation. Twenge and colleagues (2012) found that compared to previous generations, recent college students believe they outperform their peers in areas such academic ability, leadership, public speaking, writing ability, and self-confidence. Specifically, men increased more than women in self-evaluations of academic ability and women increased more than men in the area 'drive to achieve' (Twenge, Campbell, \& Gentile, 2012). These two findings together may explain the increase in perceived stress shown by the women and the significantly lower perceived stress by the men. The greater the men's self-evaluation of their ability and therefore the greater the perceived control, the less stressful life events would be. When the women report greater drive for achievement, but did not show a corresponding increase in the self-evaluation of their abilities, this may lead to greater perceived stress in life.

In addition to sex differences for freshman and seniors, there was no mitigating effect of empowerment as measured by EES for these two groups. This finding is supported by a recent study by Strahler and colleagues (2016) which reported that only in conditions of low chronic stress is there a buffering effect of exercise. The authors hypothesize that in times of higher chronic stress, physical activity may become simply one more task to accomplish or in the case of the present group - one more class to attend (Strahler et al., 2016). The question of the effectiveness of instructional physical activity for those reporting high chronic stress was left unanswered. Other groups also found no stress-moderating effect of exercise, specifically aerobic exercise and weight lifting, although some with high stress seemed to report decreased depressive symptoms while participating in ball sports and dancing (Knowlden et al., 2016; Gerber et al., 2016; Ngyen-Michel et al., 2006). This is in contrast to other findings of the relationship between exercise and life stress. Barney, Benham, and Haslem (2014) suggested a positive relationship between IPAC and stressors. However, it is useful to note that the questions were a self-report of the student's feelings about the IPAC rather than a validated scale. The final answer remains inconclusive, however only half of all published articles examined in a review of literature reported a stress-moderating effect of PA (Gerber et al., 2016).

This is the first time to the authors' knowledge GPA has been examined as a predictor of life stress in college-aged students. The results show that for freshman and seniors the greatest stress occurs in those with the lowest GPA. This is hardly surprising. The need to do well in college has been driven into college students for years. Poor performance by students would be expected to cause greater amounts of stress. This may be explained by considering the potential unique stressors associated with the year in school: lower GPA for seniors may be a significant cause for concern as it may determine eligibility for graduate and professional schools. It also indicates poorer performance in the major-specific courses taught at the highest levels with the most demands.

Freshman may experience more stress as a result of significant life changes - moving away from home, roommates, expanded adult responsibilities, differing academic expectations as compared to the K-12 environment, as well as a myriad of other potential stressors. Given these higher stress levels for first-year students and the inconclusive nature of the role of physical activity in mitigating that stress, it is not surprising to find no effect of increased empowerment in exercise against the stronger influences of sex and academic performance (GPA).

While the authors referenced many studies examining physical activity, this is because there are, to date, no published articles examining exercise empowerment and what role it may play. While currently a limitation, this is an area ripe for research and may have extend to discussions of physical literacy (PL). The instrument utilized to examine concepts of empowerment in exercise may have utility in the larger discussion of PL. The questions examined in the EES address similar concepts that Whitehead and Longmuir and Tremblay have articulated as pertinent to a physically literate individual (Whitehead, 2007; Tremblay \& Lloyd, 2010).

Physical literacy is a concept gaining increased traction within physical education and health promotion. PL includes not just being physically active but also the "the motivation, confidence, physical competence, understanding, and knowledge to maintain physical activity at an individually appropriate level, throughout life" (Whitehead, 2007). Whitehead identifies PL as the lived embodiment and pathway to a bet- 
ter quality of life and parallels other literacy concepts such as mathematics, reading, and writing as basic requirements for a well-rounded individual (Whitehead, 2007). PL includes the requirement for engagement in physical activity, but also the understanding of the value that it adds to an overall healthy life, it is a lived experience. Physical literacy is a journey that an individual takes across a life-time, not a binary measure of 'have/have not.' Furthermore, it is known that people are more active in environments that promote or support PA (Tremblay \& Lloyd, 2010). If empowerment in exercise scale can examine an aspect of physical literacy then it may help to understand PL as its role in an overall healthy life.

One limitation of this cross sectional-study is that cannot be addressed with the current data was if the students who participated a 1-credit IPAC are inherently less or more stressed than their other classmates who do not take the classes. This is an important question and should be explored in future studies by surveying a random sampling of the student body on their involvement in IPAC as well as other exercise activities and how that may relate to empowerment and stress. In addition, GPA is an imperfect measure of academic performance. However, the authors can find no other easily accessed and consistent measure collegiate success.

\section{CONCLUSION}

Exercise empowerment through participation in instructional physical activity courses does not provide a simple way to reduce life stress for college students. Sex and performance in school as measured by GPA also play interacting roles to determine perceived life stress. Previous work examined the college student body as a single, monolithic entity that behaves in similar ways regardless of year in school, this has proven short sighted. Future studies should examine the broader context of physical literacy, rather than just physical activity, in order to better understand how college students can manage life stress and therefore improved control over their daily lives. The concept of empowerment may represent a stand-in for some crucial concepts of physical literacy.

\section{REFERENCES}

American College Health Association - National College Health Association (ACHA-NCHA). (Spring 2012). Undergraduate students reference group executive summary Retrieved from http://www.acha-ncha.org/docs/ ACHA-NCHA-II_UNDERGRAD_ReferenceGroup_ ExecutiveSummary_Spring2012.pdf

Beaudoin, CM, Parker, TM, Tiemersma, KL, Lewis, CA. Evaluating university physical activity courses from student and instructor perspectives. (in press). Journal of Physical Education, Recreation, and Dance.

Barney D., Benham L., \& Haslam L. Effects of college student's participation in physical activity classes on stress. (2014). American Journal of Health Studies, 29(1), 1-6.

Cohen S., \& Janicki-Deverts D. Who's stressed? Distributions of psychological stress in the United States in probability samples from 1983, 2006, and 2009. (2012).
Journal of Applied Social Psychology, 42(6), 1320-1334. https://doi.org/10.1111/j.1559-1816.2012.00900.x

Cohen S., Janicki-Deverts D., \& Miller, GE. Psychological stress and disease. (2007). Journal of the American Medical Association, 298(14), 1685-1687. https://doi. org/10.1001/jama.298.14.1685

Cohen S., Kamark T., \& Mermelstein R. A global measure of perceived stress. (1983). Journal of Health and Social Behavior, 24(4), 385-396. https://doi. org/10.2307/2136404.

Gerber M., Brand S., Elliot C., Holsboer-Trachsler E., \& Puhse U. Aerobic exercise, ball sports, dancing, and weight lifting as moderators of the relationship between stress and depressive symptoms: An exploratory cross-sectional study with Swiss university students. (2016). Perceptual and Motor Skills, 119(3), 679-697. https://doi.org/10.2466/06.PMS.119c26z4

Hepler, TJ. Decision-making in sport under mental and physical stress. (2015). International Journal of Kinesiology and Sport Science, 3(4), 1-5.

Jones K, Mendenhall S., \& Myers C.A. The effects of sex and gender role identity on perceived stress and coping among traditional and nontraditional students. (2016). Journal of American College Health, 64(3), 205-213. https://doi.org/10.1080/07448481.2015.1117462

Knowlden A.P., Hackman C.L., \& Sharma M. Lifestyle and mental health correlates of psychological distress in college students. (2016). Health Education Journal, 75(3), 370-382. https://doi.org/10.1177/0017896915589421

Lumpkin A., \& Avery M. Physical activity program survey. (1986). Journal of Teaching in Physical Education, 5(3), 185-197. https://doi.org/10.1123/jtpe.5.3.185.

Moore E.W.G., \& Fry M.D. Psychometric support for the ownership in exercise and empowerment in exercise scales. (2014). Measurement in Physical Education and Exercise Science, 18, 135-151. https://doi.org/10.1080/1 091367X.2013.875472

Nguyen-Michel S.T., Unger J.B., Hamilton J., \& Spruijt-Metz D. Associations between physical activity and perceived stress/hassles in college students. (2006). Stress and Health, 22, 179-188. https://doi.org/10.1002/smi.1094

Strahler J., Doerr, J.M., Ditzen B., Linnemann A., Skoluda N., \& Nater U.M. Physical activity buffers fatigue only under low chronic stress. (2016). International Journal on the Biology of Stress, 19(5), 535-541. https://doi.org/10. 1080/10253890.2016.1192121

Tremblay M.S. \& Lloyd, M. Physical literacy measurement: The missing piece. (2010). Physical Health Education Journal, 76(1), 26-31.

Twenge J.M., Campbell W.K., \& Gentile B. Generational increases in agentic self-evaluations among American college students, 1966-2009. (2012). Self and Identity, 11(4), 409-427. https://doi.org/10.1080/15298868.2011 .576820

Whitehead M. Physical literacy: Philosophical considerations in relation to developing a sense of self, universality and propositional knowledge. (2007). Sport, Ethics, and Philosophy, 1(3), 281-298. https://doi. org/10.1080/17511320701676916 